\title{
FAMILIAL HYPERCHOLESTEROLAEMIA- REPORT OF A FAMILY
}

\author{
Venkatesh R. Giri' ${ }^{1}$ Pranit Farande 2 , S. N. Petkar 3 , Ajit Barve ${ }^{4}$, Rikita Patel ${ }^{5}$
}

${ }^{1}$ Assistant Professor, Department of Paediatrics, Terna Medical College, Nerul, Navi Mumbai, Maharashtra. ${ }^{2}$ Assistant Professor, Department of Dermatology and Venereology, Terna Medical College, Nerul, Navi Mumbai, Maharashtra. 3 Professor and HOD, Department of Dermatology and Venereology, Terna Medical College, Nerul, Navi Mumbai, Maharashtra. ${ }_{4}^{4}$ Medical Officer, Department of Dermatology and Venereology, NMMC, Vashi, Navi Mumbai, Maharashtra.

${ }^{5}$ Resident, Department of Dermatology and Venereology, Terna Medical College, Nerul. Navi Mumbai, Maharashtra.

HOW TO CITE THIS ARTICLE: Giri VR, Farande P, Petkar SN, et al. Familial hypercholesterolaemia- report of a family. J. Evolution Med. Dent. Sci. 2018;7(12):1550-1552, DOI: $10.14260 /$ jemds/2018/350

\section{PRESENTATION OF CASE}

5 years and 3 years old male siblings presented with the complaints of multiple yellowish lesions over buttocks since 3 months noticed by Children's mother. First, they presented in paediatric OPD. After that, patients were referred to Dermatology OPD. On examination there were yellowish, firm, rubbery nodules present on both buttocks. Lesions gradually increased in number and size. There was a history of consanguinity (Third degree), but no family history of acute myocardial infarction, stroke, dyslipidaemia or xanthomas.

The developmental milestones were normal for both the children. There was no history of chest pain, breathlessness, hypertension, diabetes mellitus or hypothyroidism.

\section{DIFFERENTIAL DIAGNOSIS}

Clinical diagnosis of cutaneous xanthomas and juvenile xanthogranuloma were kept.

\section{CLINICAL DIAGNOSIS}

Based on clinical features, we wanted to rule out cutaneous xanthomas due to familial hypercholesterolaemia.

\section{PATHOLOGICAL DISCUSSION}

Both patients were investigated.

\begin{tabular}{|c|c|c|}
\hline (mg/dL) & Sibling 1 (5 years) & Sibling 2 (3 years) \\
\hline Total Cholesterol & $\mathbf{7 1 7}$ & $\mathbf{7 3 5}$ \\
\hline TG & 130 & 136 \\
\hline LDL & 545 & 590 \\
\hline HDL & 89 & 75 \\
\hline VLDL & 20 & 25 \\
\hline \multicolumn{3}{|c|}{ Table 1 } \\
\hline
\end{tabular}

(CBC) Liver enzymes, renal functions, blood glucose and uric acid reports were normal. (ECG) and Echocardiography were normal. Plasma cholesterol levels of child's parents were also raised as father's $400 \mathrm{mg} / \mathrm{dL}$ and mother's 390 $\mathrm{mg} / \mathrm{dL}$. The biopsy of skin showed flattened epidermis, evidence of foamy macrophages seen all throughout the dermis and adipocytes seen interspersed in between them. The findings were consistent with xanthoma.

'Financial or Other Competing Interest': None.

Submission 26-01-2018, Peer Review 01-03-2018,

Acceptance 08-03-2018, Published 19-03-2018.

Corresponding Author:

Dr. Venkatesh R. Giri,

Shree Balaji Hospital,

Balaai Road, Uran, Navi Mumbai-400702.

E-mail: venkigiri4@gmail.com

DOI: $10.14260 /$ jemds $/ 2018 / 350$

\section{DISCUSSION OF MANAGEMENT}

In 1939, FH was first described by Muller. ${ }^{1}$ Over thirty years later, Myant ${ }^{2}$ first documented his theory that increased serum cholesterol was due to an increase in LDL particles. Soon thereafter, Goldstein et al recognised that FH was a genetically determined defect within hepatocytes. ${ }^{3}$ Specifically, he found that the LDL-receptor precursor was not transported to the cell surface in patients with $\mathrm{FH}$; therefore, the LDL-receptors were incapable to bind LDL resulting in an extraordinary elevation in serum LDL. ${ }^{3}$ Simon Broome formed criteria for definite and possible diagnosis of FH.

Definite Familial Hypercholesterolaemia is defined as-

1. Cholesterol > $6.7 \mathrm{mmol} / \mathrm{L}[260 \mathrm{mg} / \mathrm{dL}]$ or $\mathrm{LDL}$ cholesterol $>4 \mathrm{mmol} / \mathrm{L}[155 \mathrm{mg} / \mathrm{dL}]$ in a child $<16$ years or total cholesterol concentrations $>7.5 \mathrm{mmol} / \mathrm{L}$ [290 mg/dL] or LDL cholesterol > $4.9 \mathrm{mmol} / \mathrm{L}[190$ $\mathrm{mg} / \mathrm{dL}]$ in an adult, PLUS

2. Tendon xanthoma in the patient or evidence of these signs in first- or second-degree relative, OR

3. DNA-based evidence of an LDL-receptor mutation, familial defective apo B-100 or a PCSK9 mutation.

Possible Familial Hypercholesterolaemia is defined as-

1. Criteria 1 plus 1 of 5 or 6 .

2. Family history of myocardial infarction: Below age of 50 in second-degree relative or below age of 60 in firstdegree relative.

3. Family history of raised cholesterols- $>7.5 \mathrm{mmol} / \mathrm{L}[290$ $\mathrm{mg} / \mathrm{dL}]$ in adult $1 \mathrm{st}$ or $2 \mathrm{nd}$ degree relative or $>6.7$ $\mathrm{mmol} / \mathrm{L}[260 \mathrm{mg} / \mathrm{dL}]$ in child or sibling under $16 .{ }^{4}$

The Diagnosis of Homozygous FH in our Patient was based on the Presence of-

1. Serum cholesterol levels [Sibling $1-717 \mathrm{mg} / \mathrm{dL}$, Sibling $2-735 \mathrm{mg} / \mathrm{dL}]$ with normal triglyceride levels.

2. Appearance of xanthomas in the first decade of life.

3. Hypercholesterolaemia in both parents.

Familial hypercholesterolaemia is an autosomal dominant genetic disorder. It is caused by a defect on chromosome 19 . It may be heterozygous or homozygous variety. ${ }^{5}$ Homozygous FH is clinically characterised by cutaneous xanthomas, enlarged Achilles tendons, atherosclerosis and corneal arcus, usually developing from early childhood. Tendinous xanthoma is asymptomatic, slowly enlarging subcutaneous nodules attached to tendons, ligaments, fascia and 
periosteum with normal overlying skin. Extensor tendons of hands, feet and Achilles tendons are involved more frequently. They are often found in association with severe hypercholesterolaemia and elevated LDL level (Fredrickson type 2) and occasionally in hypercholesterolaemia associated with prolonged cholestasis. ${ }^{6,7}$ Some patients with homozygous FH do not have cutaneous xanthomas but acquire tuberous or tendon xanthomas on the elbows, knees or Achilles tendons as older children or adolescents. ${ }^{8}$ The absence of xanthomas in children does not exclude the diagnosis. Arcus cornea may be present to some degree. Total cholesterol levels are usually $>500 \mathrm{mg} / \mathrm{dL}$ and can be as high as $1,200 \mathrm{mg} / \mathrm{dL}$.

The prevalence of heterozygotes is 1 in 500 in populations. Although, plasma cholesterol level is increased 2 - to 3-fold since birth, but they became symptomatic in 3rd6 th decade of life with tendon xanthoma and cardiovascular complications. 5 The major complication of homozygous FH is accelerated atherosclerosis, which can result in clinical sequelae even in childhood. Homozygous FH children often have symptoms of vascular disease before puberty, but symptoms can be atypical or go unreported. Sudden death is common.

A child with relatively normal triglycerides and a total cholesterol level $>500 \mathrm{mg} / \mathrm{dL}$ with or without cutaneous or tendon xanthomas should be suspected of having homozygous FH. Parents and other relatives should be screened for hypercholesterolaemia. Obstructive liver disease and nephrotic syndrome should be excluded. 8

Management of FH patients, especially homozygous is challenging. Genetic counselling of the family is of utmost importance. Therapeutic measures include diet modification and drugs such as statins used alone or in combination with bile acid sequestrant, fibrates and Ezetimibe. ${ }^{9}$ LDL apheresis and orthotopic liver transplantation are other available alternatives. 10

Both patients and the family were advised low cholesterol and high-fibre diet. Patients referred to Paediatric Department and were started on Atorvastatin $20 \mathrm{mg} /$ day (3year-old child) $30 \mathrm{mg} / \mathrm{dL}$ (5-year-old child). Parents were referred to Medicine Department for evaluation and management.

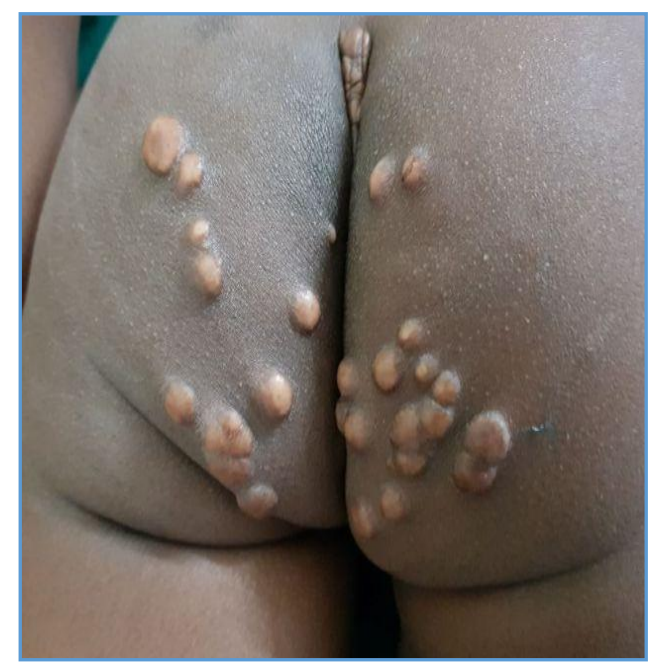

Figure 1. Image showing Xanthoma on Buttocks (5 yrs. old Male Child)

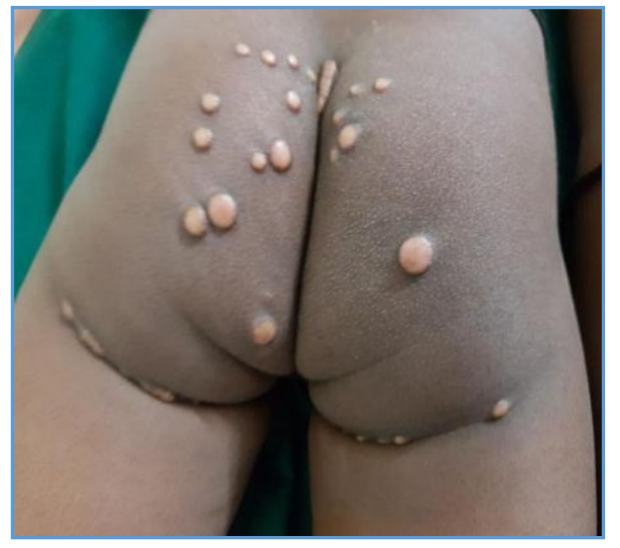

Figure 2. Image showing Xanthoma on Buttocks (3 yrs. old Male Child)

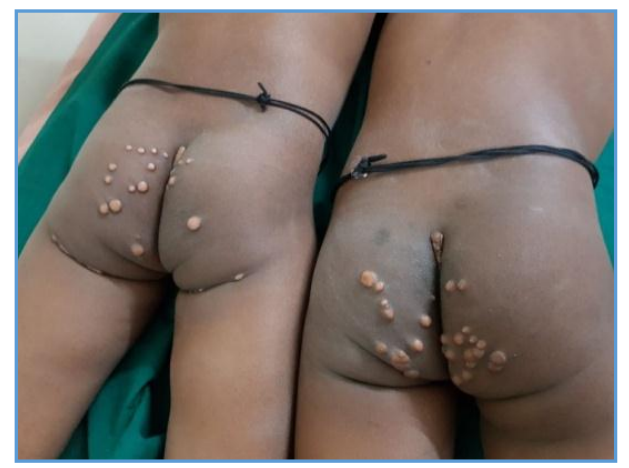

Figure 3. Image showing Xanthoma on Buttocks

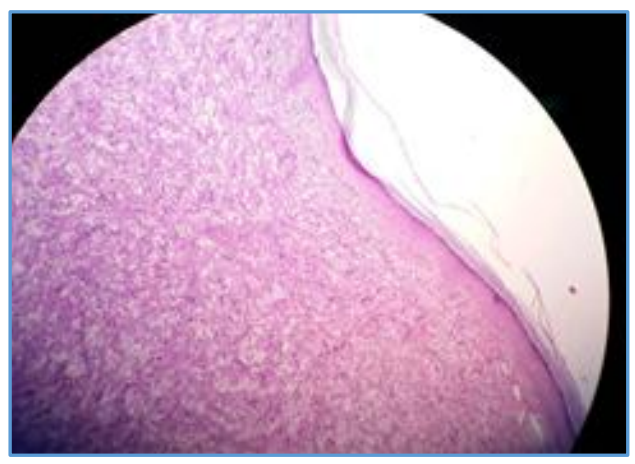

Figure 4

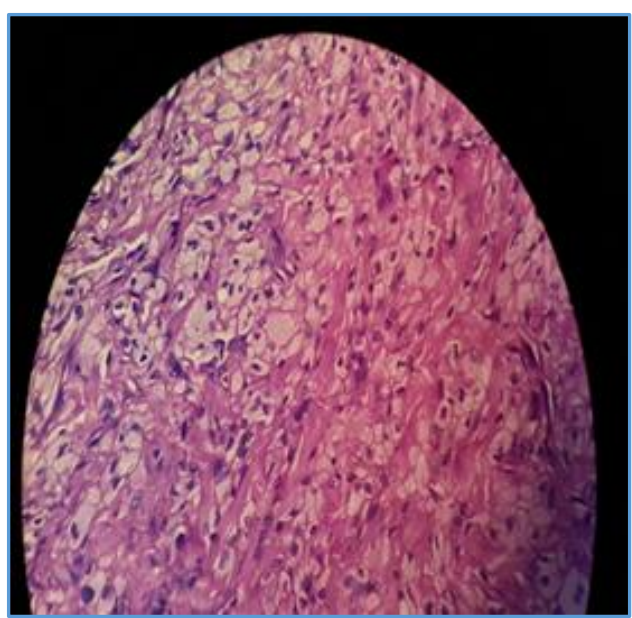

Figure 5

Figure 4 and 5. Image showing HPE of Xanthoma 


\section{FINAL DIAGNOSIS}

In view of very high LDL levels, early age of onset, high cholesterol levels in parents and histopathological findings, a final diagnosis of cutaneous xanthomas due to Homozygous Familial Hypercholesterolaemia was done in both patients.

\section{REFERENCES}

[1] Muller C. Angina pectoris in hereditary xanthomatosis. Archives of Internal Medicine 1939;64(4):675-700.

[2] Myant NB. Cholesterol metabolism. J Clin Pathol Suppl 1973;5:1-4.

[3] Goldstein JL, Hobbs HH, Brown MS. Familial hypercholesterolemia in the metabolic and molecular basis of inherited disease. Scriver CR. (eds). New York, NY, USA, McGraw-Hill, 2001:2863-913.

[4] Varghese MJ. Familial hypercholesterolemia: a review. Ann Pediatr Cardiol 2014;7(2):107-17.

[5] van Aalst-Cohen ES, Jansen AC, de Jongh S, et al. Clinical, diagnostic, and therapeutic aspects of familial hypercholesterolemia. Semin Vasc Med 2004;4(1):3141.
[6] Pandhi D, Grover C, Reddy BS. Type Ila hyperlipoproteinemia manifesting with different types of cutaneous xanthomas. Indian Pediatr 2001;38(5):550-3.

[7] Somwanshi PR, Agarwal NS. Homozygous familial hypercholesterolemia (le). Indian J Dermatol Venereol Leprol 2000;66(6):331-2.

[8] Neal WA. Nelson textbook of pediatrics. 19th edn. Elsevier, 2011:473-4.

[9] Cuchel M, Bruckert E, Ginsberg HN, et al. Homozygous familial hypercholesterolaemia: new insights and guidance for clinicians to improve detection and clinical management. A position paper from the consensus panel on familial hypercholesterolaemia of the European Atherosclerosis Society. Eur Heart J 2014;35(32):2146-57.

[10] Davidson MH. A systematic review of bile acid sequestrant therapy in children with familial hypercholesterolemia. J Clin Lipidol 2011;5(2):76-81. 